\title{
Translating the Science of Climate Change into Built Solutions
}

\author{
NATHALIE BEAUVAIS ${ }^{1,2^{*}}$, INDRANI GHOSH ${ }^{1}$, LISA DICKSON ${ }^{1}$ \\ Volume 3, Spring 2015 \\ http://dx.doi.org/10.3998/mjs.12333712.0003.010 \\ ${ }^{1}$ Kleinfelder, 215 First Street, Cambridge, Massachusetts, 02142 \\ ${ }^{2}$ Sustainable Urban Environment, Department of Landscape Architecture, Northeastern \\ University, Boston, Massachusetts, 02115 \\ *Corresponding author: Nathalie Beauvais, n.beauvais@neu.edu, nbeauvais@kleinfelder. \\ com
}

\section{ABSTRACT}

In response to anticipated climate change impacts, the City of Cambridge, Massachusetts has undertaken a study that integrates leading-edge science with real-world needs. The project employs academic research, scenario planning, risk assessment, engineering, and public health expertise to inform the City's understanding of its vulnerabilities. Key innovations include translating City-specific downscaled climate change projections to future design storm scenarios; developing comprehensive hydraulic models that links flooding from precipitation, rivers, sea level rise, and storm surge to produce a realistic representation of potential impacts during these future storm scenarios; GIS modeling to capture geospatial, social, economic, and cumulative aspects of climate change impacts; and a prioritized ranking system that compares risks across seemingly unrelated sectors (e.g., public health versus infrastructure) and assigns adaptation priorities based on this analysis. A key engineering challenge is translating the uncertainty of climate change science into design criteria that can be used to build resiliency within existing and future development. This paper documents how one city is bridging that gap and modifying design criteria to account for future extreme events. We also explore how less-quantifiable risks (socio-economic vulnerabilities and public health) are weighted and factored into this analysis. 


\section{Context for the project}

The City of Cambridge, Massachusetts is adopting a comprehensive approach that integrates science, planning, and engineering to identify the most vulnerable assets, systems, and populations. The result is a highly integrated vulnerability assessment that will form the basis for the subsequent preparedness plan. The project employs academic research, climate science, planning, risk assessment, engineering knowledge, and public health expertise to identify those areas most at risk across the built and social environments.

\section{Selecting climate scenarios}

In Phase I of this assessment, climate scenarios are based on a combination of downscaled climate projections for precipitation and temperature, localized sea level rise and storm surge projections, historic records of extreme weather events, and professional judgment regarding future stresses on existing infrastructure. Key innovations include a comprehensive model that links downscaled climate scenario-based projected flooding from surface water, piped infrastructure, sea level rise, and storm surge, while also considering the real-time operations of engineering systems focusing on the Charles River Dam and the Amelia Earhart Dam on the Mystic River. This resulted in a model of flooding impacts during projected storm events for planning horizons from 2015 to 2044 (2030s), and from 2055 to 2084 (2070s). The drainage/combined sewer system flood modeling (which uses the ICM-2D model) and the riverine flood modeling (which uses the HEC-RAS model) for future precipitation scenarios have been integrated with a statewide probability-based coastal flooding model (that uses ADCIRC/SWAN) for sea level rise and storm surge. This integrated flooding model evaluates the combined impacts of inland and coastal flooding and provides a more realistic model of storm events for the City of Cambridge. While other studies have generated flood models for existing conditions, this study makes a novel contribution by developing a comprehensive flooding model for future conditions using detailed downscaled climate change projections. Future flood elevations and depths were based on the projected 10-year and 100year floods by the 2030s and 2070s, factoring in climate change. Future changes in coastal storm climatology by the 2030s and 2070s have also been considered. This differs from the current modeling adopted by FEMA and will likely require adjustments in City planning and investments. 


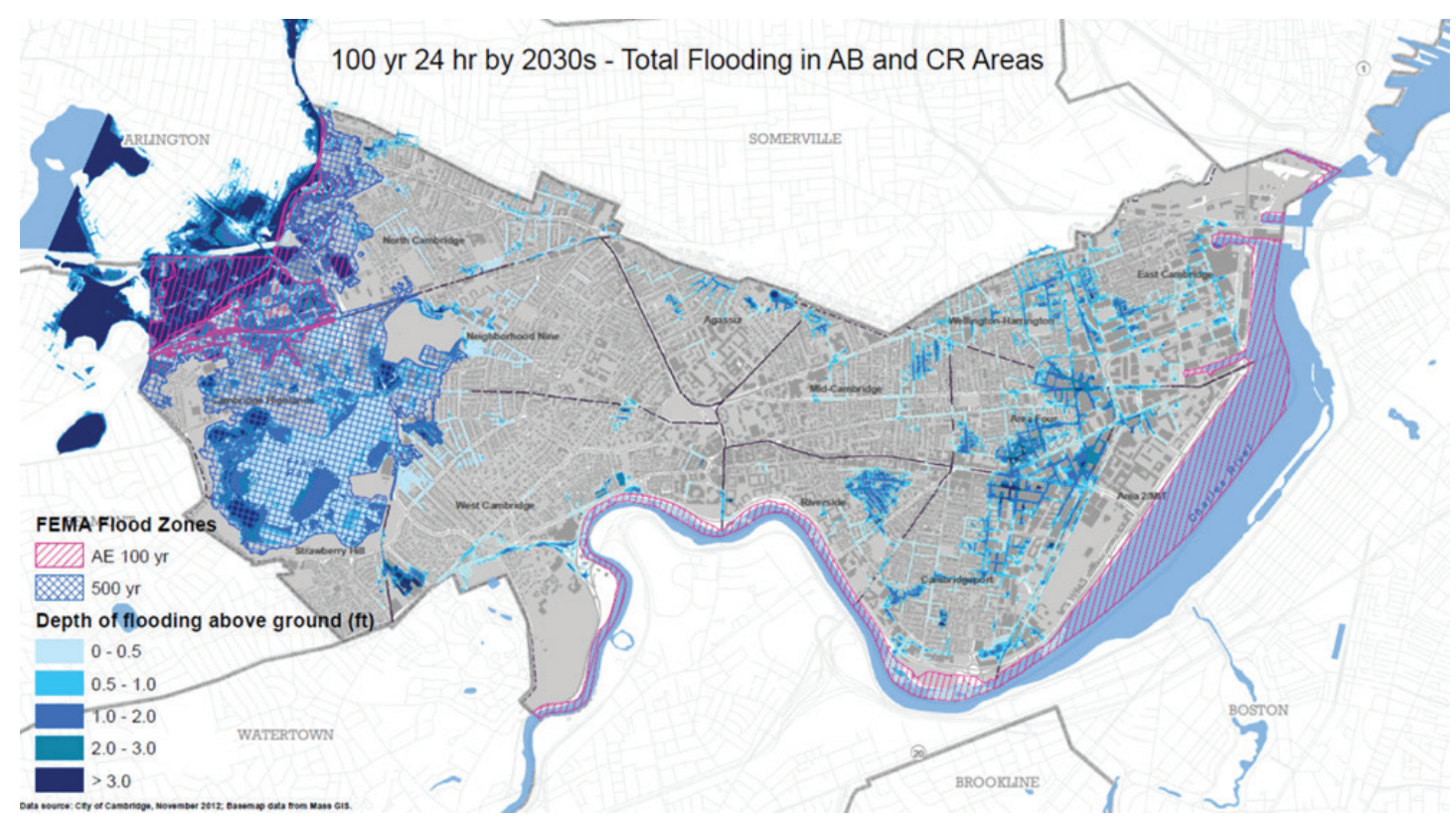

Figure 1. Projected inland flooding by the 2030s for a 100-year, 24-hour storm, "high scenario" for the City of Cambridge.

Source: Kleinfelder -- Manhole flooding by MWH, riverine flooding by VHB. (2014)

The City's consultant, Kleinfelder, is using the Geographic Information System (GIS) platform for integrating the results (in different formats and resolutions) from the riverine, piped infrastructure, and coastal flood models. The combined results of these models represent the extent and depth of flooding under future scenarios. For inland flooding, the 10 -year storms (with a 10\% annual chance of occurrence) and the 100-year storms (with a 1\% annual chance of occurrence) of 24-hour duration correspond to the lower and higher flooding scenarios, respectively (Figure 1). These inland flooding depth results also formed the basis for the economic impacts analysis using the U.S. Army Corps of Engineers Depth-Damage Function (USACOE 2006).

Using GIS, Landsat data, and hydrological data such as tree canopy cover, percent impervious surface, and elevation, the project team developed a model to map the impacts of the urban heat island (UHI) for existing conditions, as well as for the projected intensification of UHI by the 2030s and 2070s. (Julien et al. 2011) Projected trends for increased average and extreme summer temperatures for the City of Cambridge were assessed using downscaled climate projections. Historically, 11 days per year have been above $90^{\circ} \mathrm{F}$ in this region. Downscaled projections indicate 
that by the 2030s and 2070s, this number will increase by approximately three times and six times, respectively.

The downscaled climate change projections developed with the project team's academic partners are being translated into design standards by Kleinfelder. The City of Cambridge and the other team members are collaborating with many state agencies and the City of Boston to vet options for new design standards.

\section{Conducting the Risk and Vulnerability Assessment}

Phase II of the project focuses on assessing the impacts of selected plausible climate change scenarios on the City's most critical infrastructure assets. The ranking system used to identify priorities includes assessing vulnerability and risk-a two-step process - and filtering and prioritizing needs. GIS is used to analyze the primary impacts as well as cumulative and cascading points of failure to identify high-priority areas for adaptation and inform revised design criteria.

\{-?-TN: [Figure 2]\}

GIS brings a spatial dimension to the data and makes the results more understandable to key stakeholders. It does so by linking various sets of data, including model outputs from the climate projections analyses, engineering model results for flooding and infrastructure response, and social considerations such as public health, economy, and culture.

GIS enables each City's department to identify and prioritize key assets and resources through two lenses: that of the built environment, which focuses on utilities and urban infrastructures; and that of the social environment, which focuses on public health and vulnerable populations (as defined by socio-economic indicators). The key is to identify geospatial attributes of each component of the City's urban fabric and social structures whose sensitivity to flooding and heat is being measured. This measurement is possible because climate indicators are also geocoded.

The City of Cambridge is a member of ICLEI-Local Governments for Sustainability (ICLEI), an international association of governmental organizations focused on adapting to climate change. ICLEI developed a ranking system that guides users through its Climate Adaptation planning process. The Kleinfelder team is modifying the ICLEI ranking system, which is mainly qualitative, to allow Cambridge to integrate quantitative data, such as the attributes of critical assets, into its vulnerability assessment.

Cambridge's at-risk populations are also being geocoded. Vulnerability is as- 

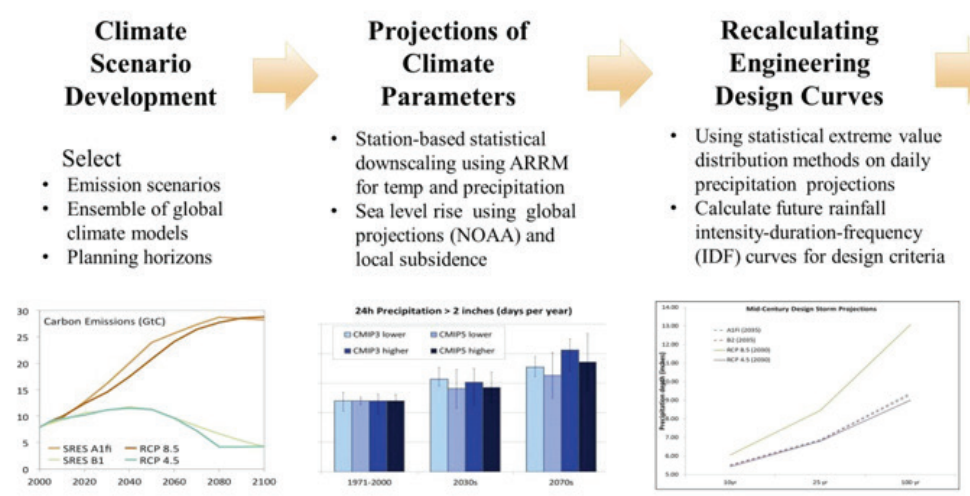

Using Revised Criteria Design and Implement Preparedness Projects
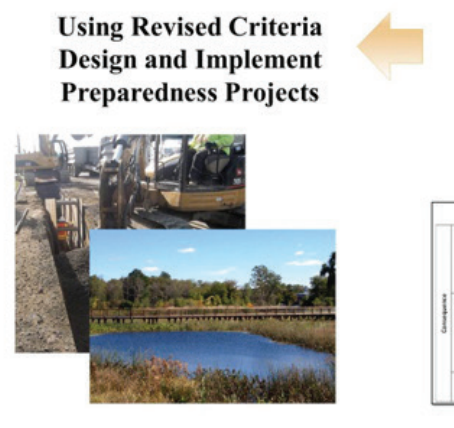

\section{Identification of Priority Planning Areas}

- Listing of high-risk areas/assets for each planning horizon

- Mapping priority planning areas in GIS

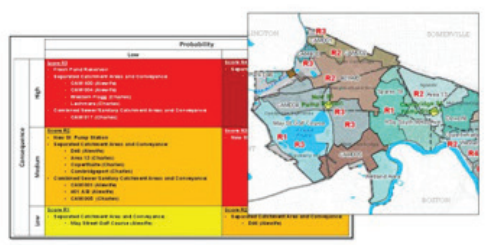

\section{Modeling Climate Change} Scenarios

- Sea level rise/storm surge using ADCIRC/SWAN Precip/riverine flooding using HEC-RAS, ICM-2D

- High temperature impacts using urban heat island modeling

- Economic impacts using MPLAN model

- Integration of model results in GIS

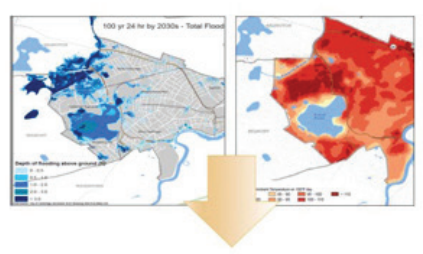

Vulnerability and Risk Assessment of Infrastructure

- Determining critical thresholds

- 2-step assessment of vulnerability / risk Using GIS and dynamic excel-based ranking tool (modified ICLEI approach)

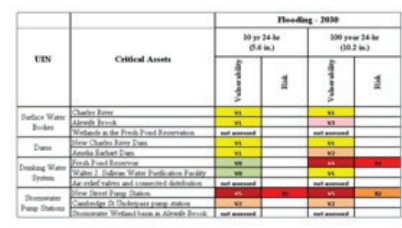

Figure 2. Process diagram illustrating how climate scenarios are used to inform assets and resources vulnerability assessment and revised design criteria.

Source: Kleinfelder (2014).

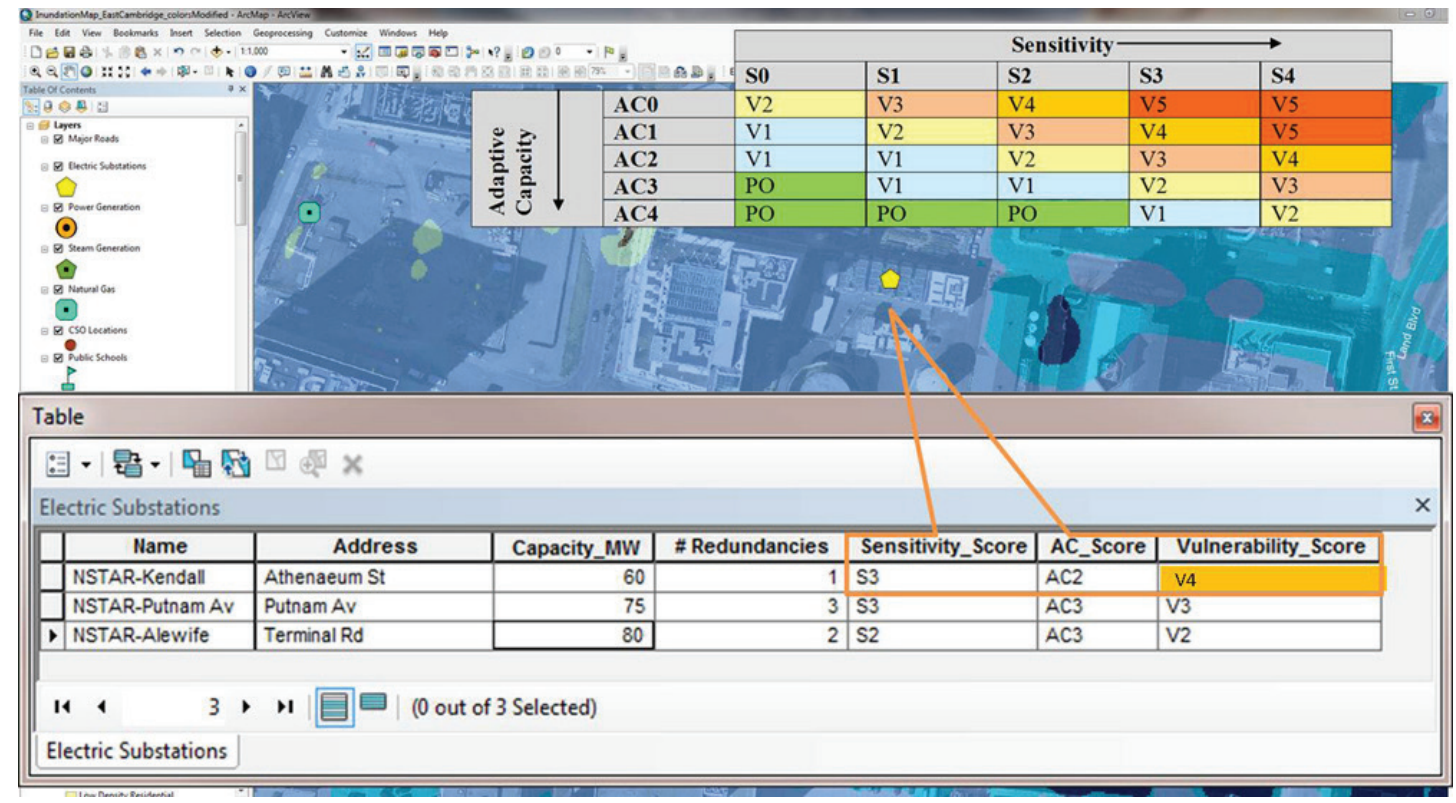

Figure 3. Example of vulnerability scoring for flooded area linking GIS and the attributes of assets.

Source: Kleinfelder (2014). 
sessed based on a combination of income level, age, health proxies, and other considerations such as language isolation and access to air conditioning. (Basu and Samet 2002) For example, a sector of the city with a greater density of senior citizens living alone is being grouped by census tracts and ranked according to the extent to which the residents will be impacted by extreme flooding and urban heat island effects. "Geocoding" all components is possible because climate indicators reported for extreme events-e.g., changing precipitation patterns; anticipated flooding, heat waves, and urban heat islands-are also mapped.

\section{Lessons learned}

The uncertainty associated with climate change and the difficulty of projecting different future scenarios create significant challenges for building resiliency to a "new normal." The range of uncertainty acceptable in a scientific study may be too broad to adequately inform new engineering criteria. A key engineering challenge is translating the uncertainty of climate science into design criteria that can be used for future urban development and revitalization.

A city-scale vulnerability assessment is a daunting task. It is challenging to prioritize critical assets to focus on a manageable number of facilities and resources, thereby enabling a city to conduct a preliminary engineering/quantitative assessment of exposure and to determine operational thresholds for early actions. A series of presentations and workshops with key stakeholders, utility providers, and city officials proved useful in developing a strategic approach to selecting critical assets and resources.

\section{References}

Basu, Rupa and Jonathan M. Samet. 2002. "Relation between Elevated Ambient Temperature and Mortality: A Review of the Epidemiologic Evidence.” Epidemiologic Reviews 24(2): 190-202.

Julien, Yves, Jose A. Sobrino, Cristian Mattar, Ana B. Ruescas, Juan C. Jimenez-Munoz, Guillem Soria, Victoria Hidalgo, Mariam Atitar, Belen Franch, and Juan Cuenca. 2011. "Temporal Analysis of Normalized Difference Vegetation Index (NDVI) and Land Surface Temperature (LST) Parameters to Detect Changes in the Iberian Land Cover between 1981 and 2001.” International Journal of Remote Sensing 32(7): 2057-2068.

USACOE (US Army Corps of Engineers). 2006. Final Report: Depth-Damage Relationships for Structures, Contents, and Vehicles and Content to Structure Value Ratios in Support of the Donaldsonville to the Gulf, Louisiana, Feasibility Study. 